05.1;06.1

\title{
Механизмы влияния углеродных нанотрубок на физические свойства полимерных композитов
}

\author{
(C) К.В. Гусев ${ }^{1}$, А.И. Ванин ${ }^{1}$, В.Г. Соловьев ${ }^{1, \uparrow, ~ V . ~ G e r b r e d e r s ~}{ }^{2}$, A. Ogurcovs ${ }^{2}$ \\ ${ }^{1}$ Псковский государственный университет, Псков, Россия \\ ${ }^{2}$ G. Liberts' Innovative Microscopy Centre, Daugavpils University, Daugavpils, Latvia \\ ฯ E-mail: solovyev_v55@mail.ru
}

Поступило в Редакцию 22 января 2020 г.

В окончательной редакции 4 марта 2020 г.

Принято к публикации 4 марта 2020 г.

\begin{abstract}
Методом сканирующей электронной микроскопии высокого разрешения получены прямые экспериментальные доказательства существования нескольких механизмов упрочнения полимерных композитов, модифицированных одностенными углеродными нанотрубками.
\end{abstract}

Ключевые слова: углеродные нанотрубки, полимерные композиты, механические свойства, сканирующая электронная микроскопия высокого разрешения.

DOI: 10.21883/PJTF.2020.11.49489.18217

Высокая механическая прочность и большое аспектное отношение углеродных нанотрубок (УНТ) открывают широкие перспективы их использования для улучшения механических характеристик композиционных материалов [1-6]. В исследованных в настоящей работе полимерных композитах [7-9] несущим конструктивным элементом материала являлось стекловолокно (ровинг), а в качестве наполнителя использовались одностенные УНТ, при малой концентрации которых ( 0.04 mass\%) удалось получить новые полимерные нанокомпозиты с улучшенными механическими свойствами. Для приготовления образцов нанокомпозитов применялись эпоксидная смола ЭД-20, отвердитель и концентрат (паста) TUBALL MATRIX на основе одностенных УНТ диаметром $d=1.6 \pm 0.4 \mathrm{~nm}$ и длиной $l>5 \mu \mathrm{m}$ (компания OCSiAL, Новосибирск). Методика получения образцов нанокомпозитов подробно описана в работах $[8,9]$, а средние механические характеристики стекловолокна, контрольного образца (не содержащего УНТ) и образцов нанокомпозита представлены в таблице. При этом значения коэффициента вариации (отношения среднего квадратичного отклонения к приведенному в таблице результату), характеризующего разброс экспериментальных данных, в среднем составили 6\% для предела прочности на разрыв, $10 \%$ для предела прочности на изгиб и $1 \%$ для модуля упругости.

Как видно из приведенных экспериментальных данных, при введении УНТ в малой концентрации удается увеличить предел прочности образцов как на разрыв, так и на изгиб на $20-30 \%$.

Значительный научный и практический интерес представляет вопрос о том, каким именно образом УНТ влияют на механические свойства полимерных композитов. В литературе [3,7-18] рассматриваются различные механизмы упрочнения композита в результате введения наполнителя. К ним относится, в частности, усиление межфазного взаимодействия волокон с матрицей $[8,9,16]$. Упрочнение композитов при введении УНТ можно объяснить размерным эффектом наноадгезии [3]. При формировании механических свойств многофазных нанокомпозитов, для которых характерны многочисленные поверхности раздела, важнейшую роль играет межфазное взаимодействие [10], причем межфазные области (как и сами УНТ) служат армирующим элементом структуры полимерных нанокомпозитов.

Цель настоящей работы - получить прямые экспериментальные подтверждения существующих модельных представлений о механизмах упрочнения полимерных композитов, модифицированных одностенными углеродными нанотрубками.

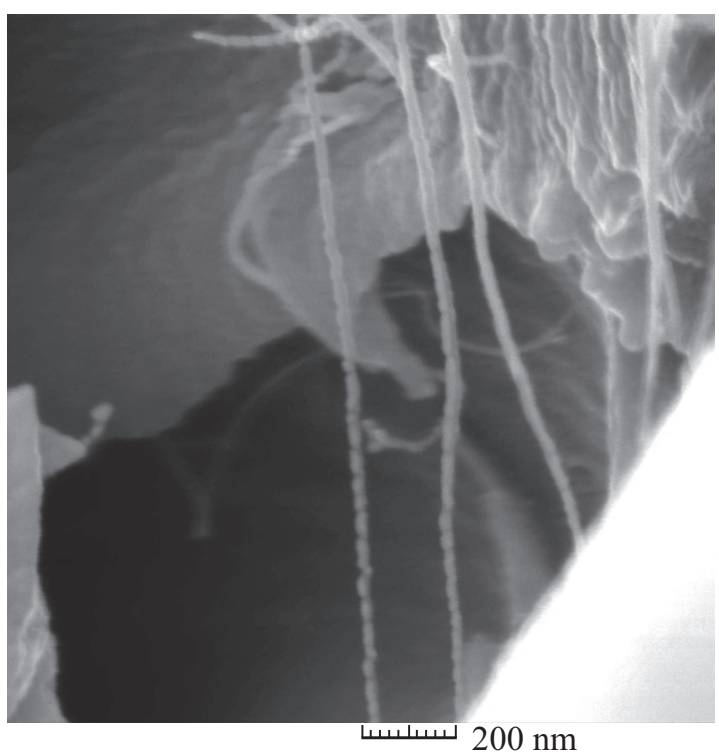

Рис. 1. СЭМ-изображение полимерных „нанобусинок“, нанизанных на УНТ. 
Механические характеристики исследованных образцов

\begin{tabular}{c|c|c|c|c}
\hline $\begin{array}{c}\text { Тип образца, марка пасты } \\
\text { TUBALL MATRIX }\end{array}$ & $\begin{array}{c}\text { Массовая концентрация } \\
\text { УНT } W_{\mathrm{CNT}}, \text { mass\% }\end{array}$ & $\begin{array}{c}\text { Предел прочности } \\
\text { на разрыв } \sigma_{1}, \mathrm{MPa}\end{array}$ & $\begin{array}{c}\text { Предел прочности } \\
\text { на изгиб } \sigma_{2}, \mathrm{MPa}\end{array}$ & $\begin{array}{c}\text { Модуль упругости } \\
E, \mathrm{GPa}\end{array}$ \\
\hline Стеклянные нити (ровинг) & - & 1970 & - & 78.8 \\
Контрольный образец & 0 & 1103 & 615 & 51.6 \\
MATRIX 301 & 0.02 & 1333 & 708 & 53.5 \\
MATRIX 301 & 0.04 & 1456 & 646 & 54.2 \\
MATRIX 301 & 0.08 & 1412 & 795 & 53.9
\end{tabular}

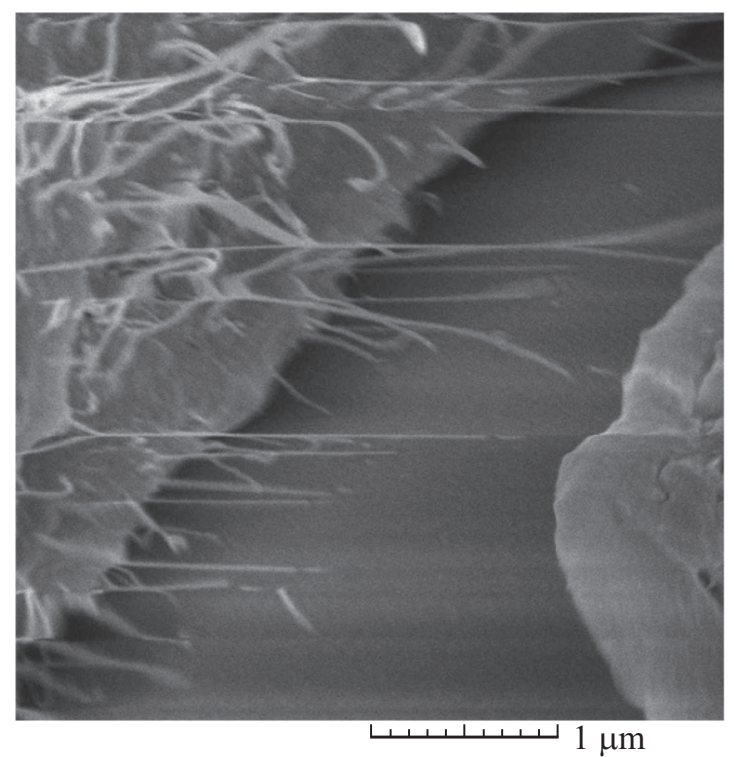

Рис. 2. СЭМ-изображение углеродных нанотрубок в виде „мостиков“, предотвращающих развитие микротрещин в образце нанокомпозита.

Наличие сильного взаимодействия УНТ с полимерной матрицей подтверждается результатами изучения структуры образцов методом атомно-силовой микроскопии $[8,9]$, в результате чего нам удалось обнаружить протяженные структуры в виде „нанобусинок“ (предположительно полимерных) диаметром порядка $50 \mathrm{~nm}$, нанизанных на углеродную нанотрубку. В настоящей работе существование подобных структур подтверждено также с помощью сканирующей электронной микроскопии $(\mathrm{CЭM)} \mathrm{высокого} \mathrm{разрешения} \mathrm{(см.} \mathrm{рис.} \mathrm{1,} \mathrm{который}$ был получен с помощью сканирующего электронного микроскопа Tescan MAIA3 Triglav). Мы полагаем, что наличие таких протяженных структур с рифленой поверхностью обеспечивает хорошее сцепление УНТ с матрицей композита. Этот механизм подобен совместной работе стальной арматуры с периодическим профилем и бетона, обеспечивающей их сцепление по поверхности контакта в структуре железобетона.

Углеродные нанотрубки, обладающие уникальными механическими характеристиками [14], могут также играть роль „мостиков“", предотвращающих развитие микротрещин. Прямым доказательством этого служит СЭМ-изображение, представленное на рис. 2, которое наглядно демонстрирует работу данного механизма в исследованных нами полимерных композитах. При этом в соответствии с теорией [11-14] матрица способна нагрузить УНТ до предельного напряжения при условии, что длина нанотрубки превышает определенное критическое значение. Как показывает расчет $[8,9]$, в нашем случае это условие выполняется.

В работе [7] установлено, что введение одностенных углеродных нанотрубок в многокомпонентные полимерные композиционные материалы на основе эпоксидной смолы может по-разному влиять на предельную температуру эксплуатации этих нанокомпозитов в зависимости от концентрации УНТ. Углеродные нанотрубки в малой концентрации в основном нарушают исходную структуру эпоксидной матрицы, препятствуя сшиванию полимерных цепочек и понижая тем самым как температуру стеклования, так и температуру последующего перехода из стеклообразного в высокоэластичное состояние. С ростом концентрации УНТ в связи с началом процесса агломерации нанодобавок может воз-

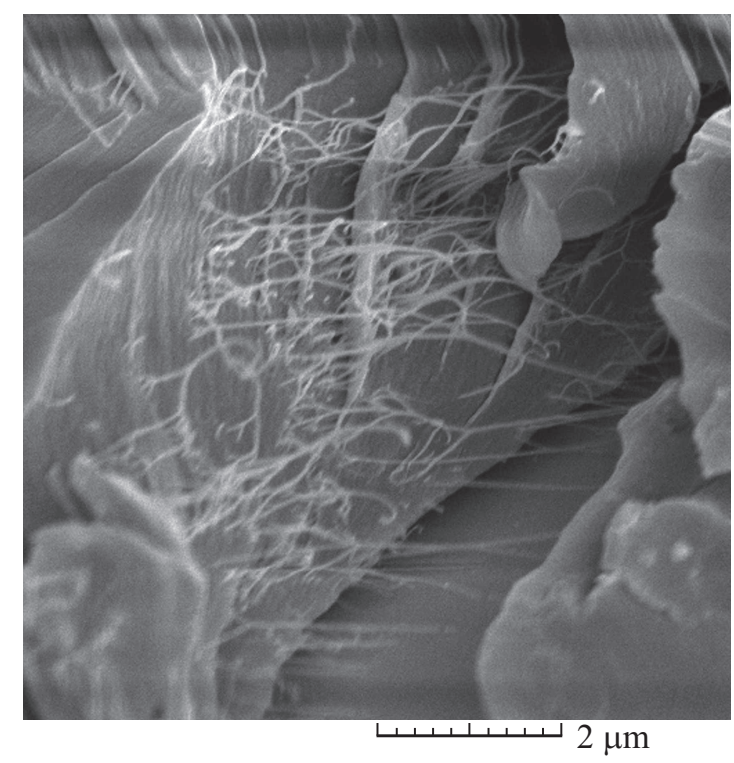

Рис. 3. СЭМ-изображение сложной структуры из УНТ в образце нанокомпозита. 
никать новая упрочняющая структура, вследствие чего термостойкость композита увеличивается. Возможность появления такой структуры иллюстрирует рис. 3 .

Следует отметить, что СЭМ-изображения УНТ, подобные представленным на рис. $1-3$, удавалось наблюдать лишь на продольных, но не на поперечных сечениях образцов нанокомпозитов. Этот факт согласуется с высказанным в [9] предположением об анизотропии расположения углеродных нанотрубок в образце, когда они ориентируются преимущественно вдоль стеклянных нитей ровинга.

Таким образом, с помощью сканирующей электронной микроскопии высокого разрешения удалось подтвердить модельные представления о механизмах влияния углеродных нанотрубок на механические свойства полимерных композитов.

\section{Благодарности}

Авторы глубоко признательны сотрудникам компании OCSiAL (Новосибирск) за предоставление высококачественных одностенных углеродных нанотрубок, а также В.В. Осташеву за полезные обсуждения.

\section{Конфликт интересов}

Авторы заявляют, что у них нет конфликта интересов.

\section{Список литературы}

[1] Polymer nanocomposites / Eds Y.-W. Mai, Z.-Z. Yu. Cambridge: Woodhead Publ., 2006. 608 p.

[2] Микитаев А.К., Козлов Г.В., Заиков Г.Е. Полимерные нанокомпозиты: многообразие структурных форм и приложений. М.: Наука, 2009. 278 с.

[3] Козлов Г.В. // УФН. 2015. Т. 185. № 1. С. 35-64.

[4] Пул Ч., мл., Оуэнс Ф. Нанотехнологии. М.: Техносфера, 2010. $336 \mathrm{c}$.

[5] Елецкий А.В., Книжник А.А., Потапкин Б.В., Кенни X.M. // УФН. 2015. Т. 185. № 3. С. 225-270.

[6] Аборкин А.В., Хорьков К.С., Объедков А.М., Кремлев К.В., Изобелло А.Ю., Волочко А.Т., Алымов М.И. // Письма в ЖТФ. 2019. Т. 45. В. 2. С. 22-25.

[7] Ванин А.И., Гусев К.В., Соловьев В.Г. // Вестн. Псков. гос. ун-та. Сер. Естественные и физико-математические науки. 2019. B. 15. C. 106-110.

[8] Gusev K., Gerbreders V., Ogurcovs A., Solovyev V. // Environment. Technology. Resources. Proc. of the 12th Int. Scientific and Practical Conf. Rezekne, Latvia, 2019. V. III. P. $48-51$.

[9] Гусев К.В., Соловьев В.Г. // Материаловедение. 2020. № 3. C. 29-34.

[10] Kozlov G.V., Dolbin I.V. // Inorgan. Mater.: Appl. Res. 2019. V. 10. N 1. P. 226-230.

[11] Микитаев А.К., Козлов Г.В. // Физика и механика материалов. 2015. Т. 24. № 2. С. 187-193.

[12] Kelley A., Davies G.J. // Met. Rev. 1965. V. 10. N 37. P. 1-77.

[13] Kelly A., Tyson W.R. // J. Mech. Phys. Solids. 1965. V. 13. N 6. P. 329-350.
[14] Zare Y. // Mech. Mater. 2015. V. 85. P. 1-6.

[15] Lutz V., Duchet-Rumeau J., Godin N., Smail F., Lortie F., Gérard J.F. // Eur. Polymer J. 2018. V. 106. P. 9-18.

[16] Leopold C., Augustin T., Schwebler T., Lehmann J., Liebig W.V., Fiedler B. // J. Colloid Interface Sci. 2017. V. 506. P. 620-632.

[17] Xiao C., Tan Y., Wang X., Gao L., Wang L., Qi Z. // Chem. Phys. Lett. 2018. V. 703. P. 8-16.

[18] Pukánszky B. // Composites. 1990. V. 21. N 3. P. 255-262. 